\title{
Tomaattia ympäri vuoden välivalojen ja väli-istutusten avulla
}

\author{
Mona-Anitta Riihimäki \\ Martensin Puutarhasäätiö, Vaasantie 1615,64610 Ylimarkku,mona.riihimaki@martens.fi
}

Vuoden 2005 alussa alkoi Närpiössä, Martensin puutarhasäätiöllä, projekti "Martens Kompetenscenter för Växthusbranschen”, eli puutarha-alan osaamiskesku -hanke. Projektin ensimmäinen hanke on elokuussa 2005 istutettu koe, jossa ensimmäistä kertaa tutkimusolosuhteissa yhdistetään viljely hattukouruissa, välivalot, sekä väli-istutukset. Tavoitteena on vuoden 2007 elokuulle jatkuvassa kokeessa selvittää edellä mainittujen viljelyteknisten ratkaisujen toimivuutta olosuhteissa, jotka ovat mahdollisimman lähellä nykyaikaista käytännön tomaattiviljelmää. Meneillään olevan tutkimuksen ensisijaisena tarkoituksena on tuoda suoraan viljelijöille tieteellisesti pätevin menetelmin testattua tietoa viljelytekniikoiden toimivuudesta ja kannattavuudesta.

Normaalisti ylös asennettujen valojen alla kasvien alemmat vihreät lehdet jäävät varjoon ja yhteyttämisen sijaan kuluttavat käytettävissä olevia kasvin resursseja. Kun osa valoista lasketaan alas nk. välivaloiksi, säteilyä suunnataan myös alalehdille ja yhteyttäminen tehostuu. Väli-istutusten tarkoitus on mahdollistaa sadontuotanto keskeytyksettä vuoden läpi ja seuraavalle kaudelle.

Tomaatin väli-istutuskoe toteutetaan lasihuoneessa, jonka viljelypinta-ala on $1810 \mathrm{~m}^{2}$. Istutustiheys on 2,6 tainta/m $\mathrm{m}^{2}$. Kohdelajikkeena on "Encoré" (de Ruiter Seeds). Kasvualustat on sijoitettu hattukourujen päälle, joiden korkeus käytävästä on n. $90 \mathrm{~cm}$. Käsittelyt kokeessa: 3 väliistutusta/vuosi, 2 väli-istutusta, sekä kontrolli, joka istutetaan uudelleen kerran vuodessa. Valaistuksessa käytetään suurpainenatriumlappuja, joiden asennusteho on $240 \mathrm{~W} / \mathrm{m}^{2}$ (ylävalot 160 $\mathrm{W} / \mathrm{m}^{2}$, välivalot $80 \mathrm{~W} / \mathrm{m}^{2}$ ).

Koejärjestely on täysin satunnaistettujen lohkojen koe (Completely Randomized Blocks). Väliistutuskokeen 1944 tainta istutettiin viikolla 34. Kustakin käsittelystä sato kerätään 12 pisteestä kolme kertaa viikossa. Kullakin keräyskerralla punnitaan kokonaissato, ja tomaatit lajitellaan kaupan laatuluokkiin. Kerran kuukaudessa suoritetaan lajittelu kokoluokkiin. Valaistuksesta, lämmityksestä, tehdystä työstä ja taimista aiheutuvia kustannuksia seurataan läpi kokeen eri väli-istutusmallien taloudellisen kannattavuuden selvittämiseksi.

Norjassa Särheimin maatalouden tutkimusasemalla on saavutettu välivaloja ja väli-istutuksia käyttäen yli $100 \mathrm{~kg} / \mathrm{m}^{2}$ vuosisato. Tämä on asetettu tavoitteeksi myös Martensin Puutarhasäätiön kaksivuotisessa kokeessa. Alustavassa välivaloja ja hatturännien käyttöä testaavassa koeviljelyssä vuoden 2005 ensimmäisellä puolikkaalla (tammi-elokuu) saavutettiin keskimäärin 1,7 kg/m viikkosato ilman väli-istutuksia. Vuoden aikaan keskeytyksettä uudistettavassa kasvustossa $100 \mathrm{~kg} / \mathrm{m}^{2}$ lienee siten realistinen tavoite myös Närpiössä käynnissä olevalle kokeelle.

Asiasanat: Tomaatti, ympärivuotinen tuotanto, väli-valot, väli-istutus 


\section{Johdanto}

Tomaatin alhaiset tuottajahinnat kesäaikaan ovat saaneet useat viljelijät investoimaan keinovaloihin ja siirtymään tomaatin talviviljelyyn. Ilman keinovaloa tomaatin ympärivuotinen viljely ei maassamme ole mahdollista loppusyksyn ja keskitalven alhaisten auringon säteilymäärien vuoksi. Kesäaikaan kasvuston hallinta on usein hankalaa runsaan valon ja kohonneiden lämpötilojen vuoksi. Lisäksi perinteisessä tomaattiviljelyssä kasvusto on kesäkuukausina jo vanhaa, mikä entisestään hankaloittaa kasvien resurssein tehokasta suuntaamista hedelmien tuotantoon. Tällä hetkellä talvitomaattia viljellään maassamme yhteensä noin 20 hehtaarin alalla. Parhaimmillaan keinovaloviljelmillä ylletään noin $75 \mathrm{~kg} / \mathrm{m}^{2}$ vuosituotantoon.

Vuoden 2005 alussa alkoi Närpiössä, Martensin puutarhasäätiöllä, projekti "Martens Kompetenscenter för Växthusbranschen". Projektin tarkoituksena on luoda kasvihuonetuotannon osaamiskeskus keskelle aluetta, jolla tuotetaan 70\% maamme tomaateista. Projektin ensimmäinen hanke on elokuussa 2005 istutettu koe, jossa ensimmäistä kertaa tutkimusolosuhteissa yhdistetään viljely hattukouruissa, välivalot, sekä väli-istutukset. Tavoitteena on vuoden 2007 elokuulle jatkuvassa kokeessa selvittää edellä mainittujen viljelyteknisten ratkaisujen toimivuutta olosuhteissa, jotka ovat mahdollisimman lähellä nykyaikaista käytännön tomaattiviljelmää. Meneillään olevan tutkimuksen, sekä koko osaamiskeskus-projektin, ensisijaisena tarkoituksena on tuoda suoraan viljelijöille tieteellisesti pätevin menetelmin testattua tietoa viljelytekniikoiden toimivuudesta ja kannattavuudesta.

Projektin määrärahoilla on Martensin Puutarhasäätiön $2000 \mathrm{~m}^{2}$ tutkimuskasvihuone nykyaikaistettu lisäämällä huoneeseen välivalojärjestelmä ja ylösnostetut hattukourut. Maatalouden tutkimuskeskuksen puutarhatuotannon yksikössä tehdyissä alustavissa kokeissa todettiin tomaatin sadon nousevan keskimäärin $16 \%$ käytettäessä välivaloja ylävalojen kanssa verrattuna normaaliin ylävaloasennukseen (Näkkilä 2005). Välivalojen on havaittu lisäävän kokonaissatoa myös kurkulla ja paprikalla (Hovi 2005 a, b). MTT:n tutkimuksissa on havaittu kasvihuonevihannesten nettofotosynteesin olevan suoraan riippuvainen käytettävissä olevasta yhteyttämisen kannalta tehokkaan säteilyn määrästä. Normaalivalaistuksessa varjossa olevat alemmat vihreät lehdet yhteyttävät erittäin vähän, ja tuottamisen sijaan kuluttavat käytettävissä olevia resursseja. Välivaloilla säteilyä suunnataan myös alalehdille, ja yhteyttäminen tehostuu. Väli-istutusten tarkoitus on mahdollistaa sadontuotanto keskeytyksettä vuoden läpi ja seuraavalle kaudelle.

\section{Aineisto ja menetelmät}

Tomaatin väli-istutuskoe toteutetaan lasihuoneessa, jonka viljelypinta-ala on $1810 \mathrm{~m}^{2}$. Viljelyjärjestelmänä käytetään paririvejä, joissa istutustiheys on 2,6 tainta/ $\mathrm{m}^{2}$. Kohdelajikkeeksi on valittu valoviljelyssä yleisimmin Suomessa käytetty tomaattilajike "Encoré" (de Ruiter Seeds). Kasvualustana kokeessa on Grodan Master Dry -kivivilla. Kasvualustat on sijoitettu hattukourujen päälle, joiden korkeus käytävästä on $n .90 \mathrm{~cm}$. Käsittelyt kokeessa ovat: kolme väli-istutusta / vuosi, kaksi väli-istutusta / vuosi ja kontrolli, joka istutetaan uudelleen vain kerran vuodessa (Kuva 2).

Keinovaloina käytetään suurpainenatriumlappuja, joiden kokonaisasennusteho on $240 \mathrm{~W} / \mathrm{m}^{2}$. Valaistusjärjestelmä on esitetty kuvassa 1 . Valaistuksesta $160 \mathrm{~W} / \mathrm{m}^{2}$ on asennettu n. $4,8 \mathrm{~m}$ korkeudelle jokaisen käytävän yläpuolelle. Kolmasosa valaistustehosta, eli $80 \mathrm{~W} / \mathrm{m}^{2}$ on sijoitettu paririvien väliin pystysuoraan käytävänpintaan nähden. Välivalojen alaosa on täysikasvuisessa tomaattikasvustossa noin $180 \mathrm{~cm}$ korkeudella. Välivaloja pystytään nostamaan ja laskemaan tarpeen mukaan. Yhteyttämisen kannalta aktiivisen säteilyn (PAR-säteily) määrää tullaan seuraamaan eri-ikäisissä kasvustoissa. 


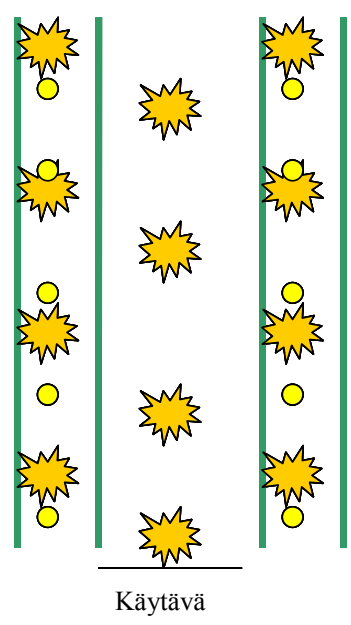

$M_{3}$ Ylävalot, $160 \mathrm{~W} / \mathrm{m} 2,400 \mathrm{~W}$ suurpainenatriumlamput,

$\mathrm{w}^{3}$ Korkeus käytävästä $\sim 420 \mathrm{~cm}$, lamppuväli $\sim 280 \mathrm{~cm}$

$\bigcirc$ Välivalot, $80 \mathrm{~W} / \mathrm{m} 2,250 \mathrm{~W}$ suurpainenatriumlampu,

Korkeus käytävästä $\sim 180 \mathrm{~cm}$, lamppuväli $\sim 130 \mathrm{~cm}$

Kuva 1. Martensin Puutarhasäätiön tutkimuskasvihuoneen valaistusjärjestelmä ylhäältä kuvattuna. katsottuna. Pelkästään keinovalosta saatavan yhteyttämisen kannalta tehokkaansäteilyn määräksi mitattiin kuukauden ikäisessä kasvustossa keskimäärin $216 \mu \mathrm{mol} \mathrm{m}^{-2} \mathrm{~s}^{-1}$.

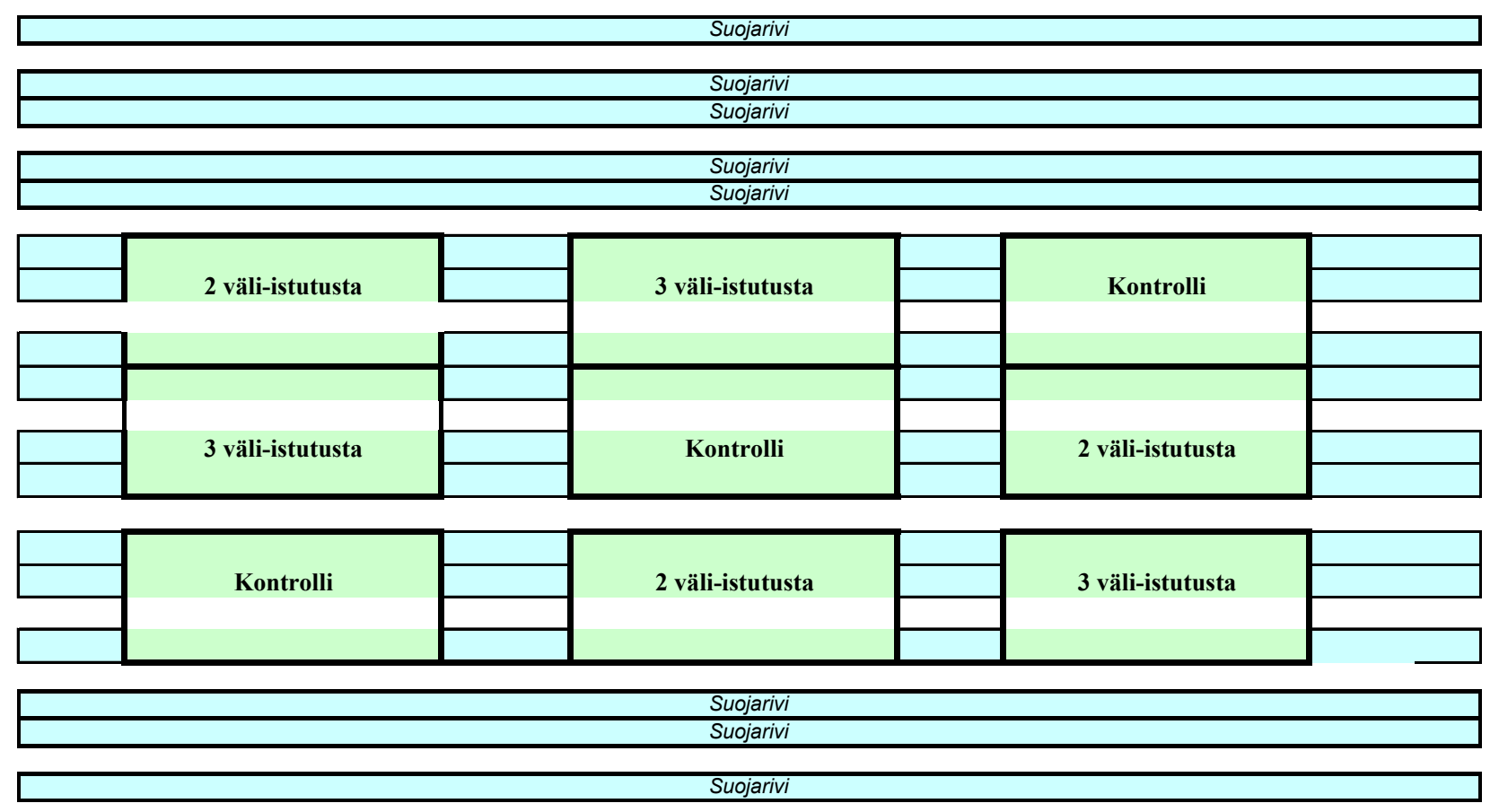

Kuva 2. Väli-istutuskokeen koejärjestely. Kukin koeruutu koostuu 216 kasvista, ja kunkin ruudun sisällä on satunnaisesti 12 keräyspistettä, joilta rekisteröidään sadonmäärä ja -laatu kolmesti viikossa. Ympäröivät vaaleansiniset alueet ovat suojakasveja.

Koejärjestely on täysin satunnaistettujen lohkojen koe (Completely Randomized Blocks). Koejärjestely on esitetty kuvassa 2 . Kustakin käsittelystä sato kerätään 12 pisteestä kolme kertaa viikossa (kukin keräyspiste käsittää yhden kasvatusalustan, jolla on 4 kasvia). Kullakin keräyskerralla punnitaan kokonaissato, ja tomaatit lajitellaan kaupan laatuluokkiin. Kerran kuukaudessa suoritetaan myös lajittelu kokoluokkiin. Väli-istutuskokeen 1944 tainta, sekä suojakasveina toimivat taimet (yhteensä 4680 latvaa), istutettiin elokuun lopussa 2005, viikolla 34. Väli-istutusten aikataulu on esitetty taulukossa 1 . Väli-istutuksia varten tutkimushuoneeseen asennetaan nykyisen 
kastelujärjestelmän rinnalle toinen järjestelmä, jolloin nuoret taimet ja vanha kasvusto pystytään kastelemaan erillisillä ravinneliuoksilla. Jo olemassa olevan kasvuton kasvualustojen välimatka on $\mathrm{n}$. $120 \mathrm{~cm}$. Väli-istutukset tehdään tyhjiin väleihin asennettuihin uusiin kivivillamattoihin. Ensimmäistä väli-istutusta varten vanha kasvusto tullaan latvomaan viikolla 49, eli kolme viikkoa ennen väliistutusten suorittamista.

Taulukko 1. Väli-istutusten aikataulu.

\begin{tabular}{lcc}
\hline \hline & 2 väli-istutusta & 3 väli-istutusta \\
\hline 2005 & elokuu & elokuu \\
& & joulukuu \\
2006 & helmikuu & huhtikuu \\
& elokuu & elokuu \\
& & joulukuu \\
2007 & helmikuu & huhtikuu \\
& Kasvuston raivaus elokuussa 2007 \\
\hline \hline
\end{tabular}

Kerran viikossa kasvua seurataan viidestä kasvista kustakin käsittelystä (yhteensä 15 kasvia). Tärkeimpiä mitattavia muuttujia ovat varren paksuus ja kukkivan tertun korkeus latvasta. Nämä muuttujat, ja niiden välinen suhde, kertovat resurssien ohjautumisesta kasvissa sen hetkisissä olosuhteissa. Tarkastelemalla muuttujia graafisesti ja huomioimalla ympäristömuuttujat (esim. ilmankosteus, lämpötila ja kastelun määrä) saadaan tukea kasvuston ohjaamiseen, ja tuleva sato pystytään ennakoimaan.

Valaistuksesta, lämmityksestä, tehdystä työstä ja taimista aiheutuvia kustannuksia seurataan läpi kokeen eri väli-istutusmallien taloudellisen kannattavuuden selvittämiseksi.

Väli-istutusten vertailu satomäärien, sadonlaadun ja kasvun osalta tullaan suorittamaan käyttänen R - ohjelmiston lineaarista sekamallia (Linear Mixed Effects, lme) (R Development Core Team 2005).

\section{Loppukommentit}

Kaksi vuotta jatkuvassa kokeessa kerätään tietoa väli-istutusten, väli-valojen ja ylösnostettujen hatturännien käytön kannattavuudesta tomaatin ympärivuotisessa viljelyssä. Kokeen alussa, ja jokaisen väli-istutusvaiheen jälkeen kutsutaan koolle alueen keinovaloja käyttävät, ja niiden käytöstä kiinnostuneet, kasvihuoneviljelijät. Yhdessä viljelijöiden kanssa keskustellaan tutkimuksen suuntaamisesta ja saaduista tuloksista, sekä tutkimuksen sovelluksista.

Norjassa Särheimin maatalouden tutkimusasemalla on saavutettu välivaloja ja väli-istutuksia käyttäen yli $100 \mathrm{~kg} / \mathrm{m}^{2}$ vuosisato. Tämä on asetettu tavoitteeksi myös Martensin Puutarhasäätiön kaksivuotisessa kokeessa. Alustavassa välivaloja ja hatturännien käyttöä testaavassa koeviljelyssä vuoden 2005 ensimmäisellä puolikkaalla (tammi-elokuu) saavutettiin keskimäärin $1,7 \mathrm{~kg} / \mathrm{m}^{2}$ viikkosato ilman väli-istutuksia. Vuoden aikaan keskeytyksettä uudistettavassa kasvustossa $100 \mathrm{~kg} / \mathrm{m}^{2}$ lienee siten realistinen tavoite myös Närpiössä käynnissä olevalle kokeelle.

\section{Kirjallisuus}


Hovi T. 2005. Esikoe paprikakasvuston alaosan valaisemisesta. Kasvihuonevihannesten yhteyttämisen tehostaminen ympärivuotisessa tuotannossa. Loppuraportti. Toim. Juha Näkkilä, Tiina Hovi, Timo Karhula, Mika Peltonen ja Risto Tahvonen. MTT.

Hovi T. 2005.Kurkun sato ja sen laatu alavalossa. Kasvihuonevihannesten yhteyttämisen tehostaminen ympärivuotisessa tuotannossa. Loppuraportti. Toim. Juha Näkkilä, Tiina Hovi, Timo Karhula, Mika Peltonen ja Risto Tahvonen. MTT.

Näkkilä J. 2005. Esikokeet tomaatin alavalotuksesta. Kasvihuonevihannesten yhteyttämisen tehostaminen ympärivuotisessa tuotannossa. Loppuraportti. Toim. Juha Näkkilä, Tiina Hovi, Timo Karhula, Mika Peltonen ja Risto Tahvonen. MTT.

R Development Core Team. 2005. R: a language and environment for statistical computing. Version 2.2.0. R Foundation for Statistical Computing, Vienna, Austria. 